\title{
PENGARUH FASILITAS KERJA TERHADAP KINERJA PEGAWAI DI DINAS PENDIDIKAN KOTA PALANGKA RAYA
}

\author{
Rintama Sitompul
}

\begin{abstract}
ABSTRAK
Sebagai upaya untuk merubah mind set dan cultur set di era Globalisasi saat ini peran Sumber Daya Manusia (SDM) sangat dituntut untuk dapat terus berkembang dalam menjawab tantangan Globalisasi. Bagi suatu bidang instansi pemerintahan yang mengutamakan pelayanan sebagi aset yang harus dijaga dan dipelihara, maka sangat ditentukan oleh tingkat performa dan mobilitas kinerja serta kemampuan SDM yang ada dalam instansi pemerintahan tersebut.

Tujuan dari penelitian ini yaitu mengetahui apakah Fasilitas Kerja (X) berpengaruh signifikan terhadap Peningkatan Kinerja Pegawai (Y) dikantor Dinas Pendidikan Kota Palangka Raya. Kajian ini dilakukan menggunakan pendekatan Kuantitatif, dimana populasi dan sampel yang dipilih adalah seluruh pegawai dikantor Dinas Pendidikan Kota Palangka Raya. Metode penelitian yang digunakan adalah teknik analisis Kuantitatif, Teknik Pengumpulan Data dengan angket (Kuisioner).

Dari hasil penelitian ini disimpulkan bahwa Pengaruh Variabel (X) Fasilitas Kerja terhadap Variabel Y (Kinerja Pegawai) pada Dinas Pendidikan Kota Palangka Raya adalah sebesar 3,6\%, 96,4\% Kinerja Pegawainya dipengaruhi oleh variabel lain, hasil penelitian ini termasuk dalam kategori Rendah.

Berdasarkan hasil dan kesimpulan yang ada diatas, maka saran yang dapat disampaikan oleh peneliti adalah bagi pihak pimpinan kantor Dinas Pendidikan Kota Palangka Raya, diharapkan untuk dapat meningkatkan Fasilitas Kerja para pegawainya.
\end{abstract}

Kata Kunci: Fasilitas Kerja, Kinerja Pegawai, Kantor Dinas Pendidikan Kota Palangka Raya

\section{PENDAHULUAN}

Perkembangan teknologi yang semakin maju menutut manusia untuk bertindak semakin cepat dengan memperhatikan efisiensi disegala bidang. Menghadapi perkembangan ini tentu saja diperlukan fasilitas atau peralatan dalam kesiapan saranya. Kalangan dunia usaha baik intansi pemerintah maupun swasta dalam menjalankan usaha sangat mengandalkan fasilitas atau peralatan kerja untuk menyelesaikan suatu pekerjaan dengan efisiensi dan hasil kerja yang optimal. Perlukan kesiapan dalam mengoperasikan fasilitas atau peralatan kerja tersebut. Karyawan atau pegawai merupakan unsur terpenting dalam menentukan maju mundurnya suatu perusahaan ataupun instansi. Untuk mencapai tujuan, diperlukan karyawan yang sesuai dengan persyaratan dalam perusahaan, dan juga mampu menjalankan tugas-tugas yang telah ditentukan oleh perusahaan atau organisasi. Setiap organisasi akan selalu berusaha untuk meningkatkan kinerja 
karyawannya dengan harapan apa yang menjadi tujuan organisasi akan tercapai. Dalam hal ini semua proses kinerja setiap karyawan sangat didukung dengan adanya fasilitas yang mendukung sehingga tujuan bisa tercapai dengan maksimal. Suatu perusahaan atau organisasi harus membuat perencanaan fasilitas dengan baik, agar fasilitas yang dipilih sesuai dengan kebutuhan. Penggunaan fasilitas yang efisien dan efektif akan mampu mempermudah pelaksanaan pekerjaan karyawan, sehingga kinerja atau produktivitas organisasi atau perusahaan akan mewujudkan tujuanya.

Dengan adanya fasilitas kerja yang baik pada Dinas Pendidikan Kota Palangka Raya dapat meningkatkan kinerja staf dan pegawai Dinas Pendidikan Kota Palangka Raya meningkat. Produktifitas yang meningkat dilihat dari cara kerja atau prosedur yang cepat. Prosedur yang cepat karena pegawai maupun karyawan memberikan pelayanan yang baik. Pelayanan yang baik dari karyawan didukung oleh adanya fasilitas kerja. Oleh karena itu perlu kiranya dilakukan sebuah penelitian yang dapat melihat seberapa baik fasilitas kerja dan kinerja pegawai di Dinas Pendidikan Kota Palangka Raya, serta bagaimana pengaruh Fasilitas Kerja terhadap Kinerja Pegawai Dinas Pendidikan Kota Palangka Raya?

\section{TINJAUAN PUSTAKA}

\section{Fasilitas Kerja}

Fasilitas kerja adalah sarana pendukung dalam aktivitas perusahaan berbentuk fisik, dan digunakan dalam kegiatan normal perusahaan, memiliki jangka waktu kegunaan yang relatif permanen dan memberikan manfaat untuk masa yang akan dating. Fasilitas kerja sangatlah penting bagi perusahaan, karena dapat menunjang kinerja karyawan, seperti dalam penyelesaian pekerjaan.

Berdasarkan definisi fasilitas diatas, maka dapat disimpulkan bahwa fasilitas adalah salah satu sarana pendukung untuk menciptakan motivasi kerja terhadap kinerja pegawai. Menurut Hartanto (2000 : 501) karakteristik dari sarana pendukung dalam proses aktivitas sebuah organisasi ataupun perusahaan adalah :

- Mempunyai bentuk fisik

- Dipakai atau digunakan secara aktif dalam kegiatan normal perusahaan

- Mempunyai jangka waktu kegunaan relative permanen lebih dari satu periode akuntansi atau lebih dari satu bulan.

- Memberikan manfaat di masa yang akan datang.

Sedangkan, indikator fasilitas menurut Faisal $(2005 ; 22)$ sebagai berikut:

- Sesuai dengan kebutuhan,

- Mampu mengoptimalkan hasil kerja,

- Mudah dalam penggunaan,

- Mempercepat proses kerja,

- Penempatan ditata dengan benar.

\section{Kinerja Pegawai}

Kinerja berasal dari kata job performance atau actual performance yang berarti prestasi kerja atau prestasi sesungguhnya yang dicapai oleh seseorang. Pengertian kinerja (prestasi kerja) adalah hasil kerja secara kualitas dan kuantitas 
yang dicapai oleh seorang pegawai dalam melaksanakan fungsinya sesuai dengan tanggung jawab yang diberikan kepadanya.

Menurut pendekatan perilaku dalam manajemen, kinerja adalah kuantitas atau kualitas sesuatu yang dihasilkan atau jasa yang diberikan oleh seseorang yang melakukan pekerjaan (Luthans, 2005:165). Terdapat beberapa faktor yang mempengaruhi kinerja :

- Efektifitas dan efisiensi

- Otoritas (wewenang)

- Displin

- Inisiatif

Lebih lanjut lagi, indikator kinerja karyawan yang diajukan oleh Robbins (2006:260) dapat digunakan untuk mengukur kinerja karyawan secara individu, yaitu:

- Kualitas

- Kuantitas

- Efektivitas

- Ketetapan Waktu

- Kemandirian

\section{METODE PENELITIAN}

Penelitian ini merupakan jenis penelitian kuantitif dimana data-data yang dianalisis berupa angka-angka (Suliyanto, 2005:134) Adapun terdapat dua sumber data berupa primer dan sekunder dengan populasi dalam penelitian ini adalah seluruh pegawai yang bekerja pada kantor Dinas Pendidikan Kota Palangka Raya dan sampelnya berjumlah 30 orang, yang ditentukan dengan menggunakan teknik Random Sampling yaitu sampel yang tidak didasarkan atas strata atau pedoman,

Karena instrumen peneliti akan digunakan untuk melakukan pengukuran dengan tujuan menghasilkan data kualitatif yang akurat, maka setiap instrumen harus mempunyai skala (Sugiyono, 2010:92). Pengukuran variabel Fasilitas Kerja dengan variabel Kinerja Pegawai menggunakan skala likert jenjang lima.

Metode pengumpulan data menggunakan metode, wawancara, dokumentasi, kuisoner yang kemudian dianalisis dengan menggunakan Uji Validitas yaitu untuk menguji daya pembeda secara signifikan digunakan rumus ttest sebagai berikut :

$$
t=\frac{X 1-X 2}{\operatorname{sgab} \sqrt{\frac{1}{n 1}}+\frac{1}{n 2}}
$$

Dimana :

$$
S g a b=\frac{\left(n_{1-1}\right) s_{1^{2}}+\left(n_{2}-1\right) s_{2}{ }^{1}}{\left(n_{1}+n_{2}\right)-2}
$$

Untuk mengetahui apakah perbedaan itu signifikan atau tidak, maa harga $t$ hitung tersebut perlu dibandingkan dengan harga $r$ tabel. Bila $t$ hitung lebih besar dengan r-tabel, maka perbedaan itu signifikan, sehingga instrumen dinyatakan valid. 
Uji yang kedua yaitu Uji Relibilitas, dan diasumsikan dengan menggunakan $\alpha=0,05$. Uji reliabilitas ini menggunakan Metode Belah Dua Sperman Brwon dengan menggunakan rumus sebagi berikut :

$r_{i}=\frac{2 \cdot r_{b}}{1+r_{b}}$

Keterangan $: r_{i}=$ Reliabilitas internal seluruh instrumen $r_{b}=$ Korelasi Product Moment

\section{HASIL DAN PEMBAHASAN}

\section{Uji Validitas Instrumen dengan Variabel Fasilitas Kerja (X)}

\begin{tabular}{|l|l|l|l|}
\hline $\begin{array}{l}\text { No item } \\
\text { Responden }\end{array}$ & $r_{\text {hitung }}$ & $r_{\text {tabel }}$ & keterangan \\
\hline 1 & 0,763 & 0,361 & Valid \\
\hline 2 & 0,652 & 0,361 & Valid \\
\hline 3 & 0,394 & 0,361 & Valid \\
\hline 4 & 0,748 & 0,361 & Valid \\
\hline 5 & 0,774 & 0,361 & Valid \\
\hline 6 & 0,741 & 0,361 & Valid \\
\hline 7 & 0,570 & 0,361 & Valid \\
\hline 8 & 0,629 & 0,361 & Valid \\
\hline 9 & 0,618 & 0,361 & Valid \\
\hline 10 & 0,598 & 0,361 & Valid \\
\hline
\end{tabular}

Berdasarkan tabel diatas bahwa dari keseluruhan 10 item untuk variabel Fasilitas kerja bisa disimpulkan bahwa setiap instrumen dinyatakan valid, dimana $r_{\text {hitung }}$ lebih besar dari $r_{\text {tabel }}\left(r_{\text {hitung }}>r_{\text {tabel }}\right)$.

\section{Reliabilitas}

Uji relibilitas ini menggunakan motede belah dua (split half method) Sperman Brown dengan rumus sebagi berikut. $r_{i}=\frac{2 \cdot r_{b}}{1+r_{b}}$

\section{Uji Reliabilitas Instrumen Fasilitas Kerja (X)}

\begin{tabular}{|l|l|l|l|}
\hline $\begin{array}{l}\text { No item } \\
\text { Responden }\end{array}$ & $\begin{array}{l}\text { Harga } \\
r_{\text {hitung }}\end{array}$ & $\begin{array}{l}\text { Harga } \\
r_{\text {tabel }}\end{array}$ & Keterangan \\
\hline 1 & 0,865 & 0,374 & Reliabel \\
\hline 2 & 0,789 & 0,374 & Reliabel \\
\hline 3 & 0,565 & 0,374 & Reliabel \\
\hline 4 & 0,855 & 0,374 & Reliabel \\
\hline 5 & 0,872 & 0,374 & Reliabel \\
\hline 6 & 0,851 & 0,374 & Reliabel \\
\hline 7 & 0,726 & 0,374 & Reliabel \\
\hline 8 & 0,772 & 0,374 & Reliabel \\
\hline 9 & 0,763 & 0,374 & Reliabel \\
\hline 10 & 0,748 & 0,374 & Reliabel \\
\hline
\end{tabular}


Dari hasil uji coba instrumen Fasilitas Kerja maka diperoleh kesimpulan bahwa dari 10 item alat ukur semua Reliabel.

\section{Uji Hipotesis Deskriptif}

Hipotesis 1.

- Fasilitas Kerja di Dinas Pendidikan Kota Palangka Raya paling rendah $60 \%$ dari yang diharapkan (skor ideal).

- Skor ideal Fasilitas Kerja yaitu : $5 \times 10 \times 30=1500$

- Skor Fasilitas Kerja di Dinas Pendidikan Kota Palangka Raya adalah 1059 (tabel no 4.11)

- Skor nilai Fasilitas Kerja di Dinas Pendidikan Kota Palangka Raya adalah $1.095: 1500=0,73 \times 100 \%=73 \%$ dari yang diharapkan ( Skor ideal).

Kesimpulannya yaitu dengan demikian hipotesis 1 (satu) yang dirumuskan dalam penelitian ini adalah : "Fasilitas Kerja di Dinas Pendidikan Kota Palangka Raya paling rendah $60 \%$ dari yang diharapkan dapat diterima.

Hiportesis 2

- Kinerja Pegawai di Dinas Pendidikan Kota Palangka Raya paling rendah $70 \%$ dari yang diharapkan (skor ideal).

- Skor ideal Kinerja Pegawai $5 \times 10 \times 30=1500$.

- Skor Kinerja Pegawai Dinas Pendidikan Kota Palangka Raya dari data hasil penelitian adalah 1181 (tabel no 4.12).

- Skor nilai Kinerja Pegawai Dians Pendidikan Kota Palangka Raya adalah

- $1.181: 1500=0,787 \times 100 \%=78,7 \%$ dari yang diharapkan (skor ideal).

Kesimpulanya yaitu bahwa hipotesis 2 yang berbunyi Kinerja Pegawai di Dinas Pendidikan Kota Palangka Raya paling rendah $70 \%$ dari yang diharapkan dapat diterima.

\section{Uji Hipotesis Assosiatif}

Berdasarkan tabel diatas :

Nilai rata-rata $\mathrm{x}=36$

nilai rata-rata $y=39$

nilai $\sum x y=135$

nilai $\sum x^{2}=363$

nilai $\sum y^{2}=1381$

$r_{x y}=\frac{135}{\sqrt{(363)(1381)}}=\frac{135}{\sqrt{501,303}}=\frac{135}{708}=0,19$

Kesimpulannya: Dari hasil perhitungan dapat diketahui bahwa terdapat hubungan yang positif sebesar 0,19 antara Fasilitas Kerja dan Kinerja Pegawai. Sesuai dengan pedoman dalam memberikan interpensi koefisien, maka Pengaruh Fasilitas Kerja Terhadap Kinerja Pegawai di Dinas Pendidikan Kota Palangka Raya tergolong rendah.

\section{KESIMPULAN}

Setelah melakukan penilitan di Dinas Pendidikan Kota Palangka Raya, maka dapat disimpulkan antara lain : 
1. Dari perhitungan data hasil penelitian untuk variabel Fasilitas Kerja adalah 73\% dari yang diharapkan, sehingga Fasilitas Kerja yang ada di Dinas pendidikan Kota Palangka Raya tergolong baik karena diatas $50 \%$ dari skor idealnya.

2. Dari perhitungan data hasil penelitian untuk variabel Kinerja Pegawai yaitu 78,7 dari yang diharapkan, sehingga Kinerja Pegawai di Dinas pendidikan Kota Palangka Raya tergolong tinggi.

3. Berdasarkan perhitungan yang didapat bahwa Pengaruh Fasilitas Kerja Terhadap Kinerja Pegawai di Dinas Pendidikan Kota Palangka Raya sebesar 3,6\%. 96,4\% Kinerja Pegawainya dipegaruhi oleh variabel lain.

4. Rendahnya pengaruh Fasilitas Kerja Terhadap Kinerja Pegawai di Dinas Pendidikan Kota Palangka Raya yang hanya 3,6\% ini sangat diluar dugaan, dimana diasumsikan bahwa semakin baik fasilitas kerja maka semakin baik pula kinerja pegawainya, namun kenyataanya hasil penelitian ini pengaruh dari kedua variabel sangat rendah.

\section{SARAN}

Berdasarkan hasil dan kesimpulan yang ada diatas, maka saran yang dapat disampaikan oleh peneliti adalag sebagai berikut :

1. Pimpinan di Dinas Pendidikan Kota Palangka Raya, diharapkan supaya lebih meningkatkan lagi Fasilitas-fasilitas yang sudah tersedia karena itu adalah salah satu untuk meningkatkan kinerja pegawai dan mempercepat sistem kerja yang ada di Dinas Pendidikan Kota Palangka Raya.

2. Dengan adanya Fasilitas yang cukup baik dan ditunjukkan dengan jawaban responden melalui kuisoner, seharusnya kinerja pegawai pada Dinas Pendidikan lebih meningkat lagi.

\section{DAFTAR PUSTAKA}

Alex S, N. (2000). Manajemen Personalia:Manajemen Sumber Daya Manusia. Jakarta: Ghalia Indonesia.

Bungin, B. (2001). Metodologi Penelitian Kuantitatif. Yogyakarta: Gaja Mada Press.

Dessler, G. (2009). Manajemen SDM. Jakarta: Indeks.

Faisal. (2005). Pengaruh Insentif dan Fasilitas Terhadap Produktivitas Pegawai. Tesis Undip.

Gomes, F. C. (2003). MSDM. Yogyakarta: Andi.

Hartanto. (2000). Produktivitas Perusahaan. Jakarta: Rajawali Press.

Hartono, L. (2000). Manajemen Personalia. Jakarta: Ghalia Indonesia.

Husnan, R. d. (2002). Manajemen Personalia. Yogyakarta: Pustakan Binawan Presindo FE UGM. 
Komar, R. (2006). Hotel Manajemen. Jakarta: Grasindo.

Luthans, F. (2005). Perilaku Organisasi, Diterjemahkan oleh :Vivin Andhika Yuono Dkk. Jakarta: Penerbit Andi.

Mangkunegara. (2002). Manajemen Sumber Daya Manusia. Bandung: PT Remaja Posda Karya.

Miles, B. Mattew \& A. Michael Huberman.2007. Analisis Data Kualitatif. Jakarta: Universitas Indonesia (UI-Perss).

Moeheriono. (2014). Pengukuran Kinerja Berbasisi Kompetensi. Jakarta: PT Raja Garafindo Persada.

Mulyana, D. (2008). Metodologi Penelitian Komunikasi. Bandung: Remaja Posda Karya.

Negara, 1. a. (2006). Modul Indikator Kinerja, Referensi untuk Menentukan Indikator Kinerja Instansi Pemerintah. Jakarta : Gramedia.

Prawirosentono, S. (2008). Kebijakan Kinerja Pegawai Karyawan. Yogyakarta: BPFE.

Rivai, V. d. (2005). Performance Appraisal, Sistem Yang Tepat Untuk Menilai Kinerja Karyawan dan Menigkatkan Daya Saing Perusahaan. Jakarta: rajawali pers.

Robbin, S. (2006). Perilaku Organisasi. Jakarta: PT Indeks kelompok Gramedia.

Ruky. (2002). Sistem Manajemen Kinerja . Jakarta: Gramedia Pustaka Utama.

Siagian, S. (2002). Manajemen SDM. Jakarta: Bumi Aksara.

Simanjuntak, P. J. (2005). Manajemen dan Evaluasi Kerja. Jakarta: Lembaga Penerbit FEUI.

Sugiyono. (2005). Metode Penelitian Kualitatif Kuantitatif. Bandung: Alfabeta.

Sutopo, H. B. (2002). Metodologi Penelitian Kualitatif . Surakarta: UNS Press.

Wibisono, D. (2011). Manajemen Kinerja Korporasi dan Organisasi:Panduan Penyusunan Indikator. Jakarta: Penerbit Erlangga.

Wibowo. (2011). Manajemen Kinerja. Jakarta: Raja Grafindo Persada. 